NICE, but will they help people with depression? The new National Institute for Clinical Excellence

\title{
depression guidelines
}

\author{
PAULA WHITTY and SIMON GILBODY
}

The National Institute for Clinical Excellence (NICE) guidelines on managing depression in primary and secondary care, having been in gestation since 2001, were finally delivered in December 2004. They should be widely welcomed by practitioners and people with depression alike. The guidelines are clear, concise and cover the key aspects of diagnosis and management: screening (high-risk groups only); distinguishing between mild, moderate and severe depression; assessing risk of selfharm and suicide; the benefits of 'watchful waiting' for mild depression; when to offer cognitive-behavioural therapy (mild or moderate depression); the use of selective serotonin reuptake inhibitors as first-line therapy in most circumstances; and the early use of combined treatment for severe depression. There is also guidance on maintenance treatment, and what to watch out for when discontinuing antidepressants. These are all areas of clinical uncertainty, which have provoked substantial debate in recent years. Given that the majority of people are treated in primary care, the guidelines will be most relevant there.

There is plenty of work to be done to improve care for people with depression. Although depressive disorders are common - in the UK, depression affects between $5 \%$ and $10 \%$ of individuals and is the third most common reason for consultation in general practice (Singleton et al, 2001) they may go unrecognised. Eighty per cent of patients with depression can consult with non-specific physical complaints, without spontaneously divulging the psychological nature of their problems (Kirmayer et al, 1993). It has been reported that depressive symptoms are not recognised in UK general practice in about half of attending patients with depressive disorders, ascertained by research diagnostic interview rather than questionnaire (Dowrick \& Buchan, 1995). Unrecognised major depression is associated with poor treatment outcomes (Rost et al, 1998), whereas there is evidence that early and vigorous intervention for depression improves outcome (AHCPR Depression Guideline Panel, 2000). Hence the importance of the NICE guidelines, which aim to put this research into dayto-day practice.

However, will the guidelines lead to this improvement in outcomes for people with depression? The short answer is: no, not unless organisational support in primary care for treating the vast majority of people is considerably extended, which includes enhancing the working relationship between primary and secondary care (Gilbody et al, 2002, 2003). Our systematic review of educational and organisational interventions to improve the management of depression in primary care provides the evidence base for how these guidelines should be implemented (Gilbody et al, 2002, 2003). Although the studies reviewed included sophisticated educational interventions (for example, 'academic detailing'), guideline implementation strategies were successful only when educational interventions were accompanied by an organisational intervention to enhance care, such as nurse case management (Rost et al, 2001) or collaborative and stepped care (Katon et al, 1999; Lin et al, 2000). Collaborative care includes patient and clinician education, along with shared care between primary care physicians, psychiatrists and psychologists, i.e. a substantial enhancement in the working relationship between primary and secondary care. An almost uniform feature of positive studies was the incorporation of some form of case management - usually by primary care nurses or graduate psychologists - to improve the delivery of care. In some studies, nurse involvement was of low intensity, and involved little more than brief medication counselling (Peveler et al, 1999) or psychosocial support over the telephone ('nurse telehealth care'; Hunkeler et al, 2000). In others, case management was a core ingredient of an effective complex strategy. For example, in the QuEST study (Rost et al, 2001) non-psychiatrically trained practice nurses were given training in the management of depression, and provided a level of ongoing support and monitored therapy, out-patient attendance and treatment response according to wellestablished algorithms.

The NICE guidelines do include a recommendation on telephone support for monitoring antidepressant regimens (paragraph 1.5.6.1), but not on any of the other organisational interventions that have been identified as being effective. Further, they soften this recommendation with the preamble that 'In primary care the following strategies can improve the effectiveness of treatments offered' (our italics; paragraph 1.5.6). A new section of the UK National Health Service workforce has recently come into existence - one thousand graduate primary mental health workers, as promised in the National Service Framework for mental health (Secretary of State for Health, 1999). There is a clear opportunity and evidence base to guide their role in primary care, by implementing case management and acting as a link between primary and secondary care. Although the full NICE guidelines raise the question of whether these new workers might 'potentially and significantly affect this situation' $(5.1$, p. 82$)$, the summary guideline avoids making specific recommendations for primary care trusts and mental health trusts as to what they should do. There is therefore a danger that they will sink into overstretched services without a clear vision of their role, thus making little impact.

The implication is clear for the NICE depression guidelines: local publicity and educational events, audit of the guidelines and review by the Healthcare Commission will not be enough to help more people with depression get better. To do this, investment in case management and related organisational interventions in primary care are needed, together with an enhancement of the relationship between primary and secondary care services. The new graduate primary care health workers need to be part of this investment. Let us hope that policy makers will grasp this nettle: this is a unique opportunity to improve outcomes for people with depression.

\section{DECLARATION OF INTEREST}

None. 


\section{REFERENCES}

AHCPR Depression Guideline Panel (2000)

Depression in Primary Care: Detection, Diagnosis, and Treatment. Technical Report Number 5. Rockville, MD: US Department of Health and Human Services, Public Health Service.

Dowrick, C. \& Buchan, I. (1995) Twelve month outcome of depression in general practice: does detection or disclosure make a difference? BMI, 3II, 1274-1276.

Gilbody, S., Whitty, P., Grimshaw, J. G., et al (2002) Improving The Recognition and Management of Depression in Primary Care. York: University of York.

Gilbody, S., Whitty, P., Grimshaw, J., et al (2003) Educational and organizational interventions to improve the management of depression in primary care: a systematic review. JAMA, 289, 3|45-3I5|.

Hunkeler, E. M., Meresman, J. F., Hargreaves, W. A. et al (2000) Efficacy of nurse telehealth care and peer support in augmenting treatment of depression in primary care. Archives of Family Medicine, 9, 700-708.

Katon, W., Von Korff, M., Lin, E., et al (1999) Stepped collaborative care for primary care patients with persistent symptoms of depression: a randomized trial. Archives of General Psychiatry, 56, 1109-1115.

Kirmayer, L. J., Robbins, J. M., Dworkind, M., et of (1993) Somatization and the recognition of depression

PAULA WHITTY, MB ChB, MSc, MD, MFPH, Centre for Health Services Research, School of Population and Health Sciences, University of Newcastle, Newcastle upon Tyne; SIMON GILBODY, MB ChB, DPhil, MRCPsych, Academic Unit of Psychiatry, University of Leeds, Leeds, UK

Correspondence: Paula Whitty, Centre for Health Services Research, 2 I Claremont Place, Newcastle uponTyne NE2 4AA, UK; Tel: +44 (0)I9I 222 8597; fax: +44 (0)191 2226043 ; e-mail: p.m.whitty@ncl.ac.uk

(First received 16 November 2004, accepted 7 December 2004)

and anxiety in primary care. American Journal of Psychiatry, 150, 734-741.

Lin, E. H., Von Korff, M., Russo, J., et al (2000) Can depression treatment in primary care reduce disability? A stepped care approach. Archives of Family Medicine, 9 1052-1058.

National Institute for Clinical Excellence (2004) Depression: Management of Depression in Primary and Secondary Care. Clinical Guideline 23. http: / /www. nice. org.uk/CG023NICEguideline

Peveler, R., George, C., Kinmonth, A. L., et al (1999) Effect of antidepressant drug counselling and information leaflets on adherence to drug treatment in primary care: randomised controlled trial. BMJ, 319, 612-615.

Rost, K., Zhang, M., Fortney, J., et al (1998) Persistently poor outcomes of undetected major depression in primary care. General Hospital Psychiatry 20, $12-20$

Rost, K., Nutting, P. A., Smith, J., et al (200I)

Improving depression outcomes in community primary care practice: a randomised trial of the QuEST intervention. Journal of General Internal Medicine, 16 , 143-149.

Secretary of State for Health (1999) National Service Framework - Mental Health. London: Stationery Office.

Singleton, N., Bumpstead, R., O'Brien, M., et al (200I) Office for National Statistics: Psychiatric Morbidity Among Adults Living in Private Households, 2000. London Stationery Office. 